\section{Guiding authors}

\author{
Phil Wiffen
}

This journal in line with many others provides guidance for prospective authors designed to steer the preparation of papers for submission and consideration for publication. ${ }^{1}$ Failure to follow the guidance is one of the most common reasons for rejection, so this editorial is to highlight their importance. We aim to give advice on the preparation of different types of articles, including original articles, short reports, case reports and letters, and we provide a template for case reports. At a recent editors board held at the Congress, we spent some time discussing the reporting of systematic reviews using the PRISMA tool (Preferred Reporting Items for Systematic Reviews and Meta-Analyses).

Reporting tools have grown up over recent years out of the evidence-based medicine movement as an attempt to improve the reports and therefore the utility of various study types. These have been largely adopted as policy by most major clinical journals. The first of these was for randomised controlled trials (RCTs). This is known by the acronym CONSORT (Consolidated Standards of Reporting Trials) and recognises the frequent frustration of those preparing systematic reviews in terms of extracting data from RCTs for meta-analysis. This led on to a raft of reporting guidelines (over 400 at the last count). These can all

Correspondence to Professor Phil Wiffen, Pain Research Unit, Churchill Hospital, Oxford OX3 7LE, UK; phil.wiffen@ndcn.ox.ac.uk be found on the EQUATOR (Enhancing the QUAlity and Transparency Of Health Research) network web page. ${ }^{2}$ I am personally not convinced of the need for so many but would encourage the use of PRISMA and CONSORT.

Potential authors of systematic reviews are encouraged to download the PRISMA guidance, and although this is a long document there are two important sections (also available separately on the website) $)^{2}$ that need to be observed. These are the PRISMA flow diagram, which sets out the way in which included studies were selected. More important is the PRISMA checklist, which details what elements should be included in the report. They cover all sections including the abstract, methods, results, discussion and funding. We have noted a trend in submissions to this journal where authors state they have followed PRISMA guidance and include a flow chart, but many of the elements in the checklist are missing.

Potential authors are also reminded of the limit set on tables and/or figures, set at a maximum of six. We have a facility to publish more if necessary online.

Poor-quality abstracts continue to be a challenge for editors. Issues raised in an editorial some time ago ${ }^{3}$ continue to be seen, particularly the use of percentages without the supporting data. Remember $50 \%$ can be 2 of 4 or 5000 of 10000 . Results sections are frequently poorly written, often with no details of the total number of participants or events studied.

My last comment is on the need for clear composition in good English. I sometimes get letters from disappointed authors asking why we cannot edit their paper. In short we do not have the resources for this but will undertake some copy editing where necessary. Most countries have commercial editing services who will undertake this task for a fee, and we encourage authors to use these when they think it is necessary.

I am aware of the work involved in preparing a paper for submission, and I hope that by raising these issues authors will be helped and have a smoother ride through to a successful publication.

Funding The authors have not declared a specific grant for this research from any funding agency in the public, commercial or not-for-profit sectors.

Competing interests None declared.

\section{Patient consent for publication Not required.}

Provenance and peer review Commissioned; internally peer reviewed.

(c) European Association of Hospital Pharmacists 2019. No commercial re-use. See rights and permissions. Published by BMJ.

\section{A) Check for updates}

To cite Wiffen P. Eur J Hosp Pharm 2019;26:123.

Eur J Hosp Pharm 2019;26:123.

doi:10.1136/ejhpharm-2019-001962

\section{REFERENCES}

1 EJHP. Authors, 2019. Available: https://ejhp.bmj.com/ pages/authors/ [Accessed April 2019].

2 Equator. Reporting guidelines for main study types, 2019. Available: http://www.equator-network.org/ [Accessed April 2019].

3 EJHP. Editorial on Abstracts, 2019. Available: https:// ejhp.bmj.com/content/23/3/125.full [Accessed April 2019]. 